\title{
Correction to: Beta2-Agonist Doping Control and Optical Isomer Challenges
}

\author{
Glenn A. Jacobson ${ }^{1} \cdot$ J. Paul Fawcett ${ }^{2}$
}

Published online: 23 January 2018

(C) Springer International Publishing AG, part of Springer Nature 2018

\section{Correction to: Sports Med}

https://doi.org/10.1007/s40279-016-0547-4

Page 1789, Table 1, 'Carmoterol' row: The cell entry in the 'Stereochemistry' column, which previously read:

"Racemic"

should read:

"R,R-stereoisomer"

Page 1789, Table 1, 'Indacaterol' row: The cell entry in the 'Stereochemistry' column, which previously read:

"Racemic"

should read:

"R-stereoisomer"
Page 1789, Table 1, 'Olodaterol' row: The cell entry in the 'Stereochemistry' column, which previously read:

"Racemic"

should read:

"R-stereoisomer"

Page 1789, Table 1, 'Vilanterol' row: The cell entry in the 'Stereochemistry' column, which previously read:

"Racemic"

should read:

"R-stereoisomer"
The original article can be found online at https://doi.org/10.1007/ s40279-016-0547-4.

\section{Glenn A. Jacobson}

glenn.jacobson@utas.edu.au

1 School of Medicine, University of Tasmania, Private Bag 26, Hobart, TAS 7001, Australia

2 School of Pharmacy, University of Otago, Dunedin, New Zealand 